\title{
INFLUÊNCIA DO HORÁRIO DE COLHEITA NA QUALIDADE DE SEMENTES DO ALGODOEIRO PRODUZIDAS EM TRÊS MICRORREGIÕES DO ESTADO DA PARAÍBA ${ }^{1}$
}

\author{
ADALGISA ARANHA DE SOUZA², RISELANE DE LUCENA A. BRUNO ${ }^{3}$, EGBERTO ARAÚJO³, \\ SEBASTIÃO MEDEIROS FILHO ${ }^{4}$ RUBENS FERNANDES DA COSTA ${ }^{5}$
}

\begin{abstract}
RESUMO - A operação de colheita é considerada uma das mais importantes na produção de sementes de algodão, devido a qualidade e o tipo de produto dependerem do modo e do momento em que é realizada. Foi conduzido este trabalho com o objetivo de avaliar a influência do horário de colheita na qualidade de sementes do algodoeiro, cultivar CNPA 7H, produzidas e colhidas em seis horários (7:00, 9:00, 11:00, 13:00, 15:00 e 17:00 horas) e três microrregiões do Estado da Paraíba: Tacima (Curimataú Oriental Paraibano), Guarabira (Piemonte da Borborema), em condições de sequeiro, e Diamante (alto sertão paraibano), em condições irrigadas. As sementes, foram avaliadas quanto ao grau de umidade, germinação e vigor (teste de frio e índices de velocidade germinação e de emergência em campo), além da sanidade. Fez-se uma análise de variância conjunta considerando o efeito dos horários de colheita e locais de produção. Os maiores valores de germinação e de vigor foram obtidos no campo de Tacima nos horários entre 9:00 e 15:00 horas. Sementes do algodoeiro colhidas às 7:00 e 17:00 horas apresentaram menor qualidade fisiológica, nos três campos de produção. As sementes produzidas sob condições irrigadas, apresentaram maior ocorrência fúngica, principalmente para os gêneros Aspergillus e Fusarium.
\end{abstract}

Termos para indexação: Gossypium hirsutum, sementes, horário de colheita, qualidade fisiológica.

\section{INFLUENCE OF THE HARVEST TIME ON THE SEED OF COTTON PRODUCTED AT THREE MICROREGIONS OF THE PARAÍBA STATE}

\begin{abstract}
The operations realized at harvest are important when the aim is to obtain seeds with good qualities and these processes are affected by the manner and time of their realization. This study was carried out investigate the influence of the harvest time on the quality of seeds of cotton produced in three microregions of Paraíba state. Cotton seeds, cultivar CNPA 7H, collected at different times (7:00, 9:00, 11:00, 13:00, 15:00 and 17:00 hours) and in different microregions of the state of Paraíba, Curimataú Oriental Paraibano (Tacima), Piemonte da Borborema (Guarabira) and Alto Sertão Paraibano (Diamante) were submitted to determination of the moisture content and evaluations of germination and vigour (cold test, speed of germination and field emergence). The sanitary analysis (fungi) was also performed. In the statistical analysis at first the data were considered individually of the effect of the microregions and then another analysis was done considering the effect of harvest times versus microregions. The highest values of germination and vigour were obtained in the Tacima fields which were harvest between 11:00 and 15:00 hours. Cotton seeds collected at the first (7:00) and last (17:00) times showed the least physiological quality in the three production fields. Seeds produced in Tacima presented the best physiological quality. The seeds produced in the Diamante had the highest fungi incidence, mainly of fungi of the Aspergillus flavus and Fusarium sp species.
\end{abstract}

Index terms: Gossypium hirsutum, seeds, times of harvest, physiological quality.

\footnotetext{
${ }^{1}$ Submetido em 12/02/2003. Aceito para publicação em 31/01/2004. Parte da dissertação de mestrado da primeira autora, apresentada a UFPB

${ }^{2}$ Doutoranda do Programa de Pós-Graduação em Agronomia, CCA/UFPB, 58.397 - 000, Areia, PB.
}

\footnotetext{
${ }^{3}$ Prof $^{\text {es }}$ Adjuntos do Depto. de Fitotecnia, UFPB/CCA, Cx. Postal 22; email: lane@cca.ufpb.br

${ }^{4}$ Prof. Adjunto do Depto. de Fitotecnia, UFC

5 Pesquisador da Empresa Paraibana de Pesquisa Agropecuária EMEPA/PB.
} 


\section{INTRODUÇÃO}

A cultura do algodoeiro herbáceo (Gossypium hirsutum L. r. latifolium Hutch) no Brasil é de grande importância sócio-econômica, gerando milhares de empregos de forma direta e indireta. Dentre as operações desenvolvidas com esta cultura, a colheita é uma operação de grande relevância, visto que a qualidade e o tipo de produto dependem, em grande parte, da forma e do momento em que ela é feita. $\mathrm{O}$ agricultor nordestino inicia a colheita nas primeiras horas da manhã, com o algodão ainda orvalhado e, sem nenhuma secagem prévia do material, armazena-o, temporariamente. Nessa situação a qualidade fisiológica das sementes e, consequentemente, a qualidade da fibra são afetadas pela fermentação decorrente do excesso de umidade (Queiroga et al., 1994). Por outro lado, Dutra \& Castro (1997), afirmam que o teor de água inicial das sementes de algodão, acelera a sua deterioração, além de que, o teor de água adequado à colheita é alcançado, em geral, após a semente atingir a maturidade fisiológica, ocorrendo entre esses dois estágios, perda da qualidade destas, principalmente quando expostas a fatores adversos.

A semente é um dos insumos de menor custo de produção e sua utilização é uma das estratégias para garantir a obtenção de lavoura de alto padrão de qualidade. Até atingirem umidade ideal para colheita, as sementes podem estar sujeitas a uma série de condições adversas no campo, como ataque de fungos, de insetos e, principalmente, contrações e expansões dos tecidos devido à absorção e perda de água. Essas alterações do teor de água das sementes podem ocorrer como consequiência da variação de umidade relativa diurna e noturna, do orvalho e, notadamente, da ocorrência de chuvas no período compreendido entre a maturidade fisiológica e a colheita (Peske \& Hamer, 1997). O momento adequado da colheita em função da maturação do algodoeiro, que é um dos estádios mais limitantes no desenvolvimento da semente, onde ela apresenta a máxima qualidade fisiológica, é um dos fatores mais importantes na produção de sementes de algodão (Brigante, 1992).

O presente trabalho teve como objetivo avaliar a influência do horário de colheita sobre a qualidade de sementes do algodoeiro herbáceo, cultivar CNPA 7H, produzidas em três microrregiões do Estado da Paraíba.

\section{MATERIAL E MÉTODOS}

O experimento foi conduzido em campos de produção localizados em três microrregiões do Estado da Paraíba, sendo duas em condições de sequeiro, nos municípios de Tacima e Guarabira e uma sob regime de irrigação, no município de Diamante, todos pertencentes aos cooperados do Programa de Produção de Sementes da Empresa Estadual de Pesquisa Agropecuária da Paraíba (EMEPA). Os dados meteorológicos (umidade relativa, temperatura e precipitação pluvial) encontram-se na Figura 1. Foram realizadas inspeções freqüentes nos campos selecionados para produção de sementes da cultivar CNPA $7 \mathrm{H}$ desde a semeadura à colheita; por ocasião desta, em cada campo de produção utilizou-se uma área central correspondente a 1 hectare para a realização do experimento. Essa área foi dividida em quatro blocos, com distância de 2 metros entre si, contendo cada um deles seis tratamentos. Cada parcela (unidade experimental) foi representada por seis fileiras de 50 metros, espaçadas de $1 \mathrm{~m}$, totalizando $300 \mathrm{~m}^{2}$, o que correspondeu a 2.500 plantas por parcela, colhidas das quatro fileiras centrais. A colheita foi realizada manualmente, de acordo com os seguintes tratamentos: 7:00, 9:00, 11:00, 13:00, 15:00 e 17:00 horas, com uma área total do experimento de $41,0 \mathrm{~m}$ x $206 \mathrm{~m}$, ou seja, $8.446 \mathrm{~m}^{2}$. Em cada horário, as 16 fileiras foram colhidas por 16 homens, num tempo máximo de 45 minutos. Utilizou-se delineamento em blocos casualizados, com quatro repetições. Posteriormente, o algodão em rama resultante de cada tratamento foi conduzido à Usina de Beneficiamento de Sementes da EMEPA, no município de Pirpirituba-PB.

Após a retirada das fibras, amostras de sementes de $2 \mathrm{~kg}$ foram encaminhadas aos Laboratórios de Sementes (LAS) e de Fitopatologia do Centro de Ciências Agrárias Areia/PB, para avaliação da qualidade fisiológica e sanitária, respectivamente. A qualidade fisiológica das sementes foi avaliada por meio do grau de umidade (antes e após o beneficiamento), testes de germinação e de frio, e índices de velocidade de germinação e de emergência de plântulas no campo. A avaliação da qualidade sanitária foi feita pelo método do "blotter test" (Neergaard, 1979).

As sementes, antes de serem avaliadas, foram submetidas à desinfestação com hipoclorito de sódio a 2,5\% por um período de 10 minutos, seguindo-se a mesma metodologia de Araújo Filho et al. (1993). A determinação do grau de umidade foi efetuada em estufa a $105 \pm 3^{\circ} \mathrm{C}$, durante 24 horas (Brasil, 1992), utilizando-se duas repetições de $30 \mathrm{~g}$ para cada subamostra por tratamento utilizado. $\mathrm{O}$ resultado final foi expresso em percentagem, com uma casa decimal.

Para o teste de germinação foram empregadas quatro subamostras de 50 sementes por tratamento semeadas sobre duas folhas de papel tipo germitest, umedecidas com água destilada, em quantidade equivalente a 2,5 vezes a sua massa. Em seguida, foram cobertas com mais uma folha de papel, confeccionando-se rolos, que foram levados ao germinador, onde permaneceram a $25^{\circ} \mathrm{C} \mathrm{em}$ presença de luz. As contagens das plântulas normais foram realizadas no quarto e décimo primeiro dias. Na primeira contagem foram retiradas as plântulas normais e as sementes mortas ou infectadas que pudessem servir de contaminação às 
demais. No décimo primeiro dia foi realizada a contagem final, computando-se o total de plântulas normais (Brasil, 1992). O índice de velocidade de germinação foi conduzido juntamente com o teste de germinação. As avaliações das plântulas normais foram realizadas diariamente, à mesma hora, a partir da primeira contagem de germinação. $\mathrm{O}$ índice foi calculado através da fórmula proposta por Maguire (1962).

Para o teste de frio sem solo, foi adotada a metodologia inicial do teste de germinação, quanto ao número de sementes e ao umedecimento do substrato, exceto no tocante a temperatura da água que apresentava $8^{\circ} \mathrm{C}$. As sementes após desinfestação, semeadura no substrato de papel e confecção dos rolos, foram postas em uma caixa plástica vedada e levadas à refrigeração constante $\left(8^{\circ} \mathrm{C}\right)$, por um período de sete dias. Decorrido este tempo, estas foram postas a germinar, sob condições de temperatura e luz idênticas às do teste de germinação, com contagem no quinto dia. A interpretação do teste foi feita computando-se a percentagem de plântulas normais (Vieira \& Carvalho, 1994).

Para o índice de velocidade de emergência de plântulas no campo foram utilizadas quatro subamostras de 50 sementes para cada tratamento. Cada unidade experimental constou de fileiras de $2,5 \mathrm{~m}$ de comprimento, espaçadas de $0,20 \mathrm{~m}$ entre si, com disposição em blocos ao acaso. A semeadura foi realizada a uma profundidade média de $2 \mathrm{~cm}$, e a cobertura das sementes com aproximadamente $1,5 \mathrm{~cm}$ de solo. A umidade do solo foi mantida por irrigações freqüentes (Banzatto \& Kronka, 1992). Após a instalação, foram realizadas contagens diárias de plantas normais, a partir do dia em que a primeira plântula emergiu, até o término do teste (21 dias), conforme proposto por Egli \& Tekrony (1995). O índice foi calculado através da fórmula proposta por Maguire (1962).

$\mathrm{Na}$ avaliação da micoflora das sementes foram utilizadas quatro repetições de 50 sementes, previamente desinfestadas, para cada tratamento, as quais foram incubadas empregando-se o método "blotter test", segundo Neergaard (1979). Para tanto, foram colocadas dez sementes por placa de Pétri contendo três folhas de papel de filtro previamente umedecidas e esterilizadas. Após a distribuição das sementes, as placas foram levadas a uma câmara de incubação com temperatura de $24 \pm 2^{\circ} \mathrm{C}$, permanecendo por sete dias sob efeito de luzes de frequiência próxima ao ultra violeta (N.U.V.) e fotoperíodo de 12 horas. A identificação e avaliação da incidência dos fungos foram feitas examinando-se as colônias fúngicas desenvolvidas nas sementes sob microscópio estereoscópio. Quando necessário a identificação foi complementada pela visualização das características morfológicas dos fungos em microscópio óptico e comparadas com as descrições da literatura (Singh et al., 1991).

$\mathrm{Na}$ análise estatística dos dados utilizou-se, inicialmente, a análise de variância individual para os experimentos oriundos de cada local. Em seguida, realizouse a análise de variância conjunta considerando o efeito dos horários de colheita e microrregiões. O programa estatístico utilizado foi o Sistema para Análises Estatísticas - SAEG, versão 7.0. Os dados em percentagem foram transformados em arc sen $\sqrt{x / 100}$ e as médias foram comparadas pelo teste de Duncan, a 5\% de probabilidade.

\section{RESULTADOS E DISCUSSÃO}

Foram registradas as médias mensais de umidade relativa, temperatura e precipitação pluvial nos três campos de produção, desde a semeadura à colheita (maio a outubro/1998, em condições de sequeiro e agosto/98 a janeiro/99, irrigado), verificando-se nos campos de sequeiro (Tacima e Guarabira), maior ocorrência de chuvas no mês de julho $(114,4$ e $130,3 \mathrm{~mm}$, respectivamente), estendendo-se até agosto no campo de Guarabira (Figura 1), reduzindo a partir de então, nos dois locais, até o momento da colheita. Já para o campo irrigado (Diamante), registrou-se ocorrência de chuvas apenas no mês de janeiro (94,6 mm), com umidade relativa de $79 \%$ e temperatura média de $30^{\circ} \mathrm{C}$, coincidindo com a época da colheita (Figura 1).

Os dados do grau de umidade das sementes colhidas nos diferentes horários, nas três microrregiões, revelaram valores mais elevados daquelas produzidas no município de Diamante, em todos os horários de colheita (Figura 2A), principalmente quando colhidas às 7:00 horas da manhã $(16,8 \%)$, antes do beneficiamento. As sementes desse campo foram expostas a chuvas na pré-colheita e colheita (Figura 1), contribuindo, provavelmente, para aumentar a umidade e ativar o mecanismo respiratório destas, que, sob condições climáticas desfavoráveis, concorre a um rápido processo de deterioração (Figueiredo, 1981). Cabe ressaltar que após atingir a maturidade fisiológica, as sementes se desligam fisiologicamente da planta, estando portanto, na dependência das condições climáticas, que em condições desfavoráveis (ocorrência de chuvas) poderá acelerar o processo respiratório, provocando severa deterioração pela alternância de absorção e perda de umidade, associada ao ataque de fungos patogênicos (Carvalho, 1974; Carvalho \& Nakagawa, 2000). Nos demais horários, as sementes apresentaram teor de água dentro do padrão recomendado pela CESM-PB (1989), isto é, 12\%. Após o beneficiamento, estas tenderam a ficar em equilíbrio com o meio, interagindo de acordo com sua higroscopicidade, apesar do maior grau de umidade ainda ser alcançado pelas sementes colhidas no campo de Diamante (Figura 2B). A umidade das sementes de algodão próxima de $15 \%$ pode provocar a deterioração das mesmas, comprometendo desse modo, sua qualidade fisiológica (Queiroga, et al., 1994); por outro lado, sementes com $10 \%$ de umidade, respiram 
normalmente, conservando seu potencial germinativo e vigor (Passos, 1977).

\section{TACIMA}

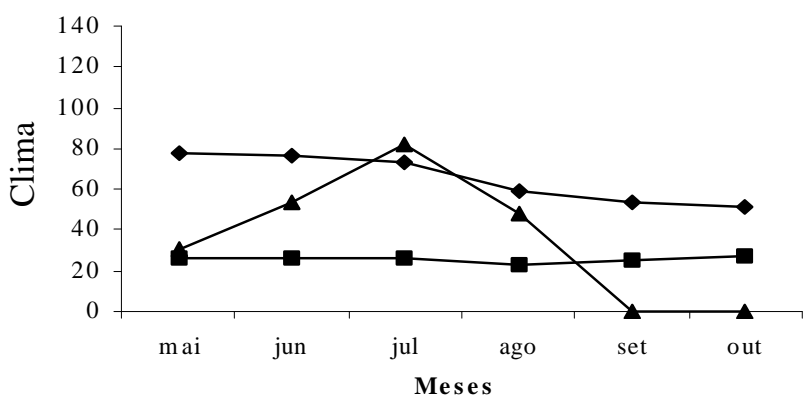

GUARABIRA

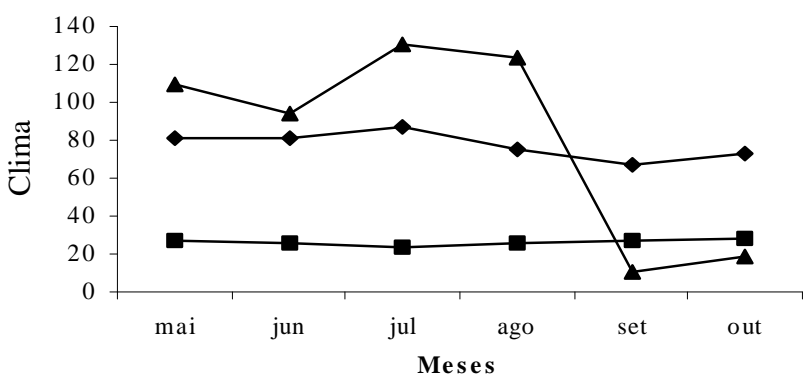

DIAMANTE

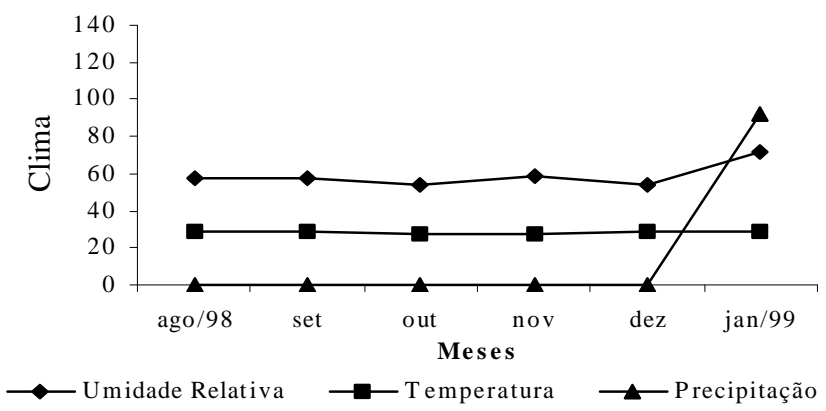

FIGURA 1. Médias mensais de umidade relativa do ar $(\%)$, temperatura $\left({ }^{\circ} \mathrm{C}\right)$ e precipitação pluvial (mm) das diferentes microrregiões (Tacima, Guarabira e Diamante) do Estado da Paraíba, do plantio à colheita. Areia, PB, 2003.

Nos municípios de Tacima e Guarabira, graus de umidade mais elevados das sementes foram observados às 7:00 horas (Figura 2A), em relação aos verificados nos demais horários de colheita; após o beneficiamento, verificou-se uniformidade entre horários de colheita e campos de produção, fato indicador do alcance do equilíbrio higroscópico (Figura 2B). Estes resultados estão de acordo com os de Peske \& Hamer (1997) que verificaram, em sementes de soja, a influência da umidade na germinação e no vigor das sementes, constatando que, normalmente, pela manhã colhe-se com umidades mais elevadas e à tarde, com a redução da umidade relativa do ar, estas, tendem a diminuir. Da mesma forma, Reuzeau \& Cavalié (1997) constataram que o grau de umidade presente na semente de girassol por ocasião da colheita, pode influenciar o teor de RNA e, consequentemente, a capacidade de síntese deste, afetando processos fisiológicos da semente. Essa alteração fisiológica causa aumento da respiração e produção de $\mathrm{CO}_{2}$ influenciando negativamente na eficiência germinativa (Bewley \& Black, 1994).

(A)
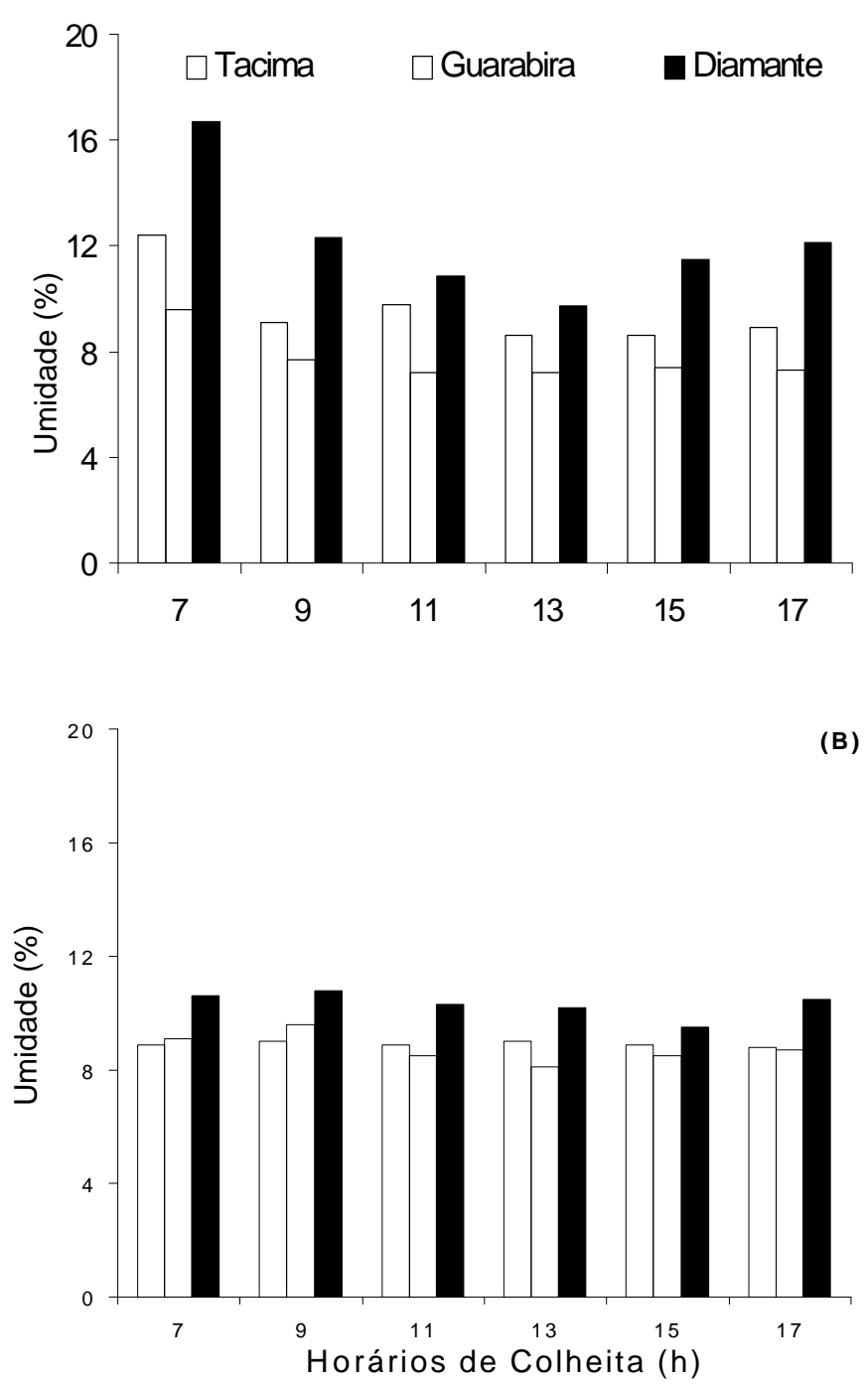

FIGURA 2. Grau de umidade de sementes do algodoeiro herbáceo, colhidas em diferentes horários e microregiões do Estado da Paraíba, antes (A) e após o beneficiamento (B).

As médias da germinação das sementes colhidas em diferentes horários e microrregiões do Estado da Paraíba 
encontram-se na Figura 3A. Sementes produzidas no campo de Tacima colhidas as 9:00 horas da manhã apresentaram maior potencial germinativo, não diferindo, estatisticamente, das sementes colhidas às 13:00 horas. No campo de Guarabira, com exceção do horário das 13:00 horas, não houve diferença significativa para as sementes colhidas nos demais horários; no campo irrigado de Diamante, o maior destaque foi para as 15:00 horas (74\%), não diferindo das 11:00 e 13:00 horas, tendo esse campo apresentado, no geral, menor potencial germinativo, provavelmente pela ocorrência de chuvas no final do ciclo da cultura (Figura 1), coincidindo com a colheita, o que poderá justificar a redução da qualidade fisiológica das sementes do algodoeiro colhidas nesse campo, a qual é altamente influenciada pelas condições climáticas sob as quais são produzidas (Tanaka \& Paolinelli, 1984; Medeiros Filho et al., 1993 e Goulart, 1995). De acordo com Bolonhezi et al. (1999), o atraso na colheita influencia a germinação e o vigor das sementes, variando em função do local de cultivo e da cultivar do algodoeiro

Não houve diferença significativa entre campos de produção para sementes colhidas às 11:00, 15:00 e 17:00 horas. As sementes, de todos os campos e dos diferentes horários atenderam ao padrão recomendado pela CESM-PB (1989) para germinação de sementes do algodoeiro (mínimo de 60\%), com exceção daquelas oriundas dos campos de Tacima e de Diamante colhidas às 7:00 horas, e de Guarabira às 13:00 horas, provavelmente pela maior infestação de pragas. Pelo exposto, os maiores percentuais ficaram compreendidos entre os horários das 9:00 às 15:00 horas.

Com relação ao vigor, avaliado pelo teste de frio (Figura 3B), os dados relativos ao campo de Tacima indicaram sementes com vigor superior quando colhidas às 9:00 horas, sem diferir das 11:00, 15:00 e 17:00 horas. No campo de Guarabira, sementes mais vigorosas foram observadas no horário das 15:00 horas, não diferindo das 11:00 e 13:00 horas; enquanto que em Diamante, os horários mais relevantes foram às 11:00, 13:00 e 15:00 horas. Comparando-se os campos de produção, verificou-se que as sementes produzidas em Tacima obtiveram maior vigor $(70-84 \%)$ que àquelas produzidas nos demais locais, em todos os horários, não diferindo entretanto, daquelas oriundas do campo de Guarabira nos horários das 13:00 e 15:00 horas. Já para o campo de Diamante, a ocorrência de chuvas coincidentes com a colheita, pode ter contribuído para a redução do vigor (18 a 42\%), em relação ao campo de Tacima com um valor máximo de $84 \%$, no teste de frio (Figura 3B). Resultados que corroboram com Cardoso Sobrinho et al. (1999), onde os mesmos salientam que, lotes de sementes de sorgo de alta qualidade devem alcançar no teste de frio um percentual de 70 a $85 \%$. Esse teste foi um dos mais convincentes em avaliar a qualidade das sementes, nas condições adversas de cada microrregião; sabendo-se que, segundo Pizzinato et al. (1999), as diferenças observadas na qualidade destas sementes, podem ser atribuídas ao manejo do campo e às condições climáticas de cada local.
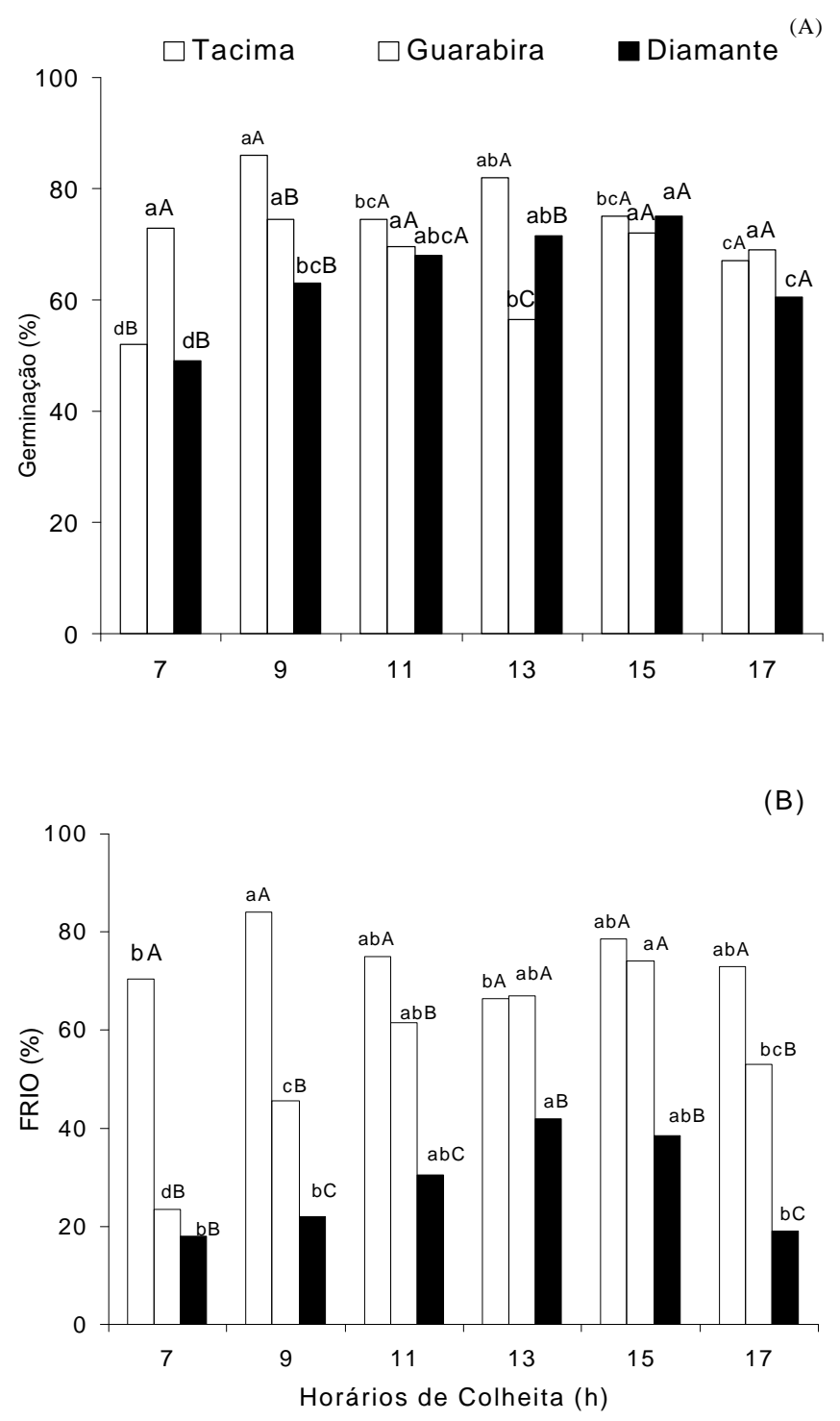

FIGURA 3. Testes de germinação (A) e de frio (B) em sementes do algodoeiro herbáceo, colhidas em diferentes horários e microrregiões do Estado da Paraíba. Médias seguidas pela mesma letra minúscula (nos diferentes horários) e maiúscula (entre os campos de produção), não diferem significativamente entre si a $5 \%$ de probabilidade pelo teste de Duncan.

Os dados referentes ao vigor estimado pelos índices de velocidade de germinação e de emergência de plântulas no campo, das sementes colhidas em diferentes horários e microrregiões do Estado da Paraíba encontram-se na Figura 4 (A e B), respectivamente. No campo de Tacima índice 
superior de velocidade de germinação, foi observado para sementes colhidas às 9:00 horas, não diferindo estatisticamente das 13:00 horas; para o campo de Guarabira, não houve diferenças de vigor das sementes colhidas nos diferentes horários, exceto para aquelas colhidas às 13:00 horas, cujo vigor foi inferior, enquanto que, para o campo de Diamante, o maior vigor foi para sementes colhidas às 15:00 horas não diferindo daquelas sementes colhidas às 11:00 e 13:00 horas. Com relação aos três campos de produção, não houve diferenças significativas entre colheitas às 11:00 e 15:00 horas, verificando-se mais uma vez, a superioridade do campo de Tacima, em relação aos demais, às 9:00 e 13:00 horas. Estes resultados estão de acordo com Silva (1999), que constatou maior vigor nas sementes do algodoeiro colhidas na mesma microrregião no segundo horário do primeiro turno (9:00 horas).

Com relação ao índice de velocidade de emergência de plântulas (Figura 4B), não houve diferença significativa entre tratamentos para o campo de Tacima. Considerando o campo de Guarabira, o menor vigor foi para sementes colhidas às 11:00 horas; e, para o local Diamante, o maior vigor foi observado às 11:00 e 13:00 horas. Relacionandose os três campos de produção, comprova-se mais uma vez, a superioridade das sementes produzidas no município de Tacima em mais um teste de vigor, que diferiu em todos os tratamentos do campo de Guarabira, com exceção de Diamante, apenas às 11:00 e 13:00 horas.

A Figura 5 refere-se a incidência de fungos mais freqüentes nas sementes colhidas nos diferentes campos de produção: Aspergillus flavus, Aspergillus sp, Fusarium sp. e Rhizopus sp. Os fungos do gênero Aspergillus, são referidos como típicos de armazenamento (Neergaard, 1979) e algumas de suas espécies são deletérios à semente do algodoeiro, contribuindo para sua deterioração precoce. O Fusarium sp., de acordo com Kimati (1980), é um dos principais fungo responsável pela decadência da cultura do algodoeiro, levando à necessidade de produção de variedades melhoradas resistentes. O Rhizopus sp., é considerado contaminante (Neergaard, 1979) porém, de acordo com Lima et al. (1995), em sementes de algodão tem causado redução da germinação e do vigor.

Os valores máximos registrados para incidência de fungos, de acordo com os campos produtores, foram de $25 \%$ em Diamante, $15 \%$ em Tacima e 10\% em Guarabira. Em Diamante, as altas precipitações pluviais no período da colheita (janeiro de 1999), e a frequiência de irrigações durante todo o ciclo da cultura, deve ter proporcionado condições mais favoráveis para a evolução destes fungos do que em Tacima e Guarabira, cujos campos foram mantidos em condições de sequeiro. Nestes, em todos os horários de colheita, as maiores incidências foram de Rhizopus sp, sendo o Aspergillus flavus, verificado nas sementes do primeiro campo, naquelas colhidas às 11:00 e 15:00 horas.

\section{Tacima Guarabira Diamante}

(A)

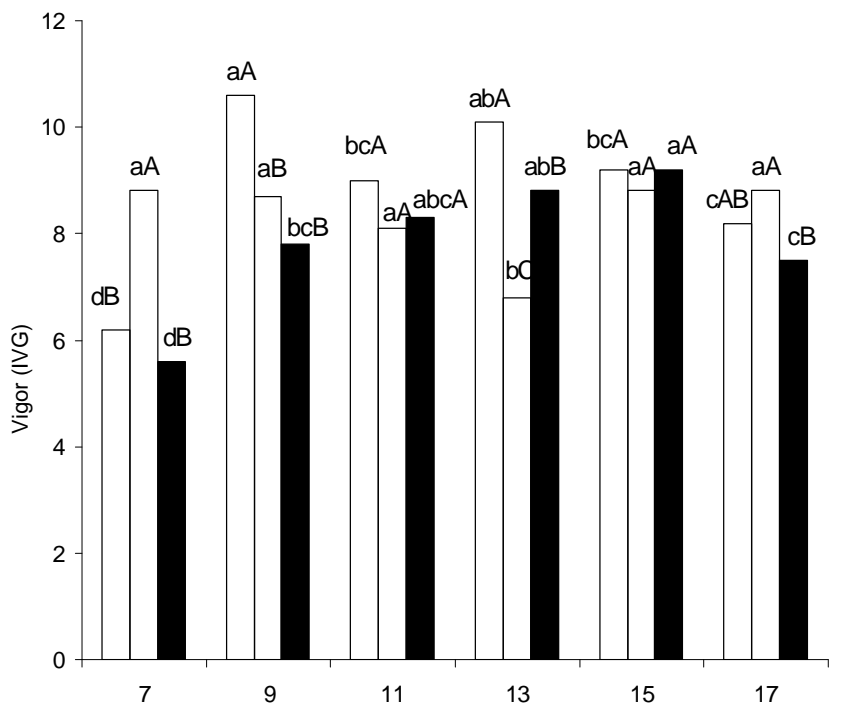

(B)

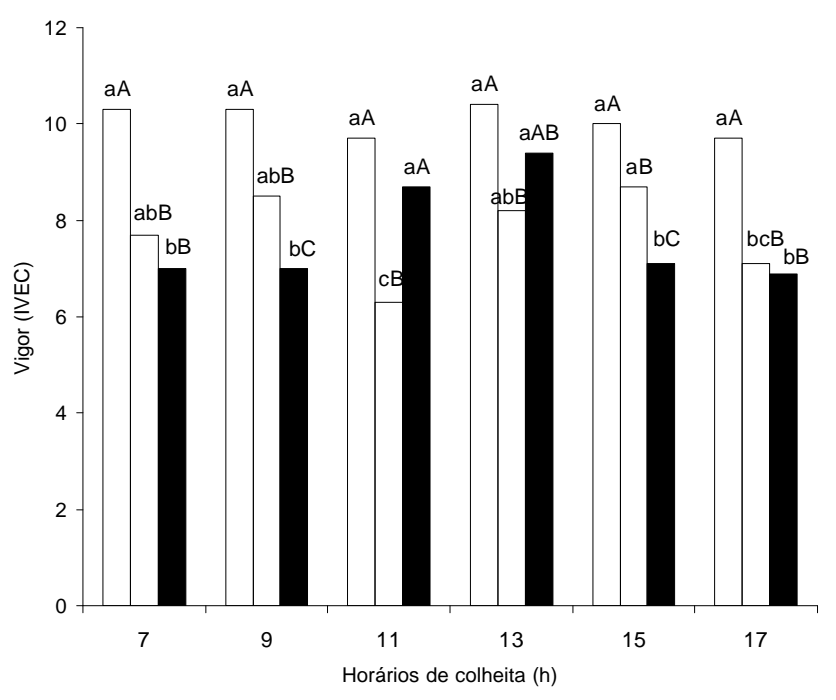

FIGURA 4. Índices de velocidade de germinação (A) e de emergência no campo (B) de sementes do algodoeiro herbáceo, colhidas em diferentes horários e microrregiões do Estado da Paraíba. Médias seguidas pela mesma letra minúscula (nos diferentes horários) e maiúscula (entre os campos de produção), não diferem significativamente entre si a $5 \%$ de probabilidade, pelo teste de Duncan. 
TACIMA

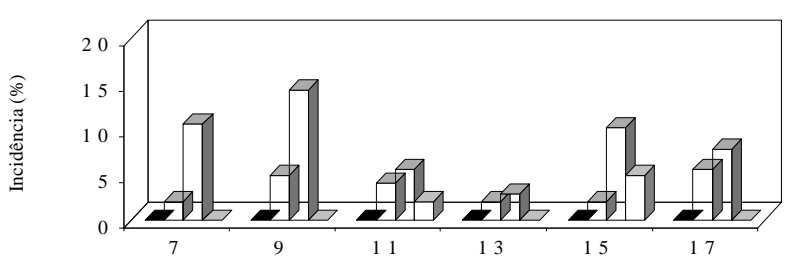

GUARABIRA

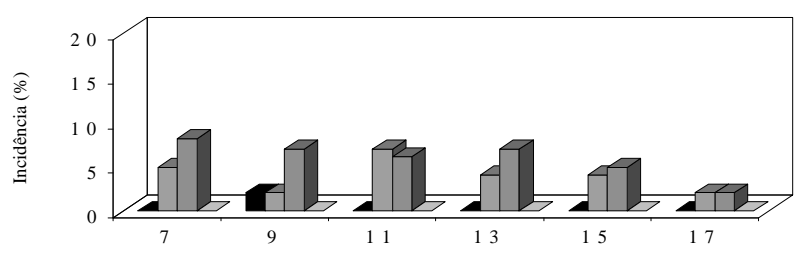

DIAMANTE

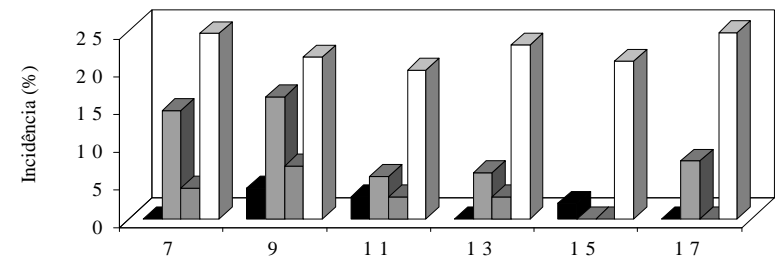

Horários de Colheita (h)

Aspergillus sp.四 Fusarium sp. 囲 Rhizopus sp. $\square$ Aspergillus flavus

FIGURA 5. Incidência de Aspergillus sp, Fusarium sp, Rhizopus sp. e Aspergillus flavus em sementes do algodoeiro herbáceo colhidas em diferentes horários nos municípios de Tacima, Guarabira e Diamante, no Estado da Paraíba.

No município de Diamante, além dos fungos já referidos, foram encontrados nas sementes, esporadicamente, Helminthosporium sp., Penicillium sp, Alternaria sp. e Curvularia sp. Neste campo, a incidência de fungos foi maior no material colhido às 7:00 e 17:00 horas. A micoflora mais numerosa e os valores de incidências mais elevados (Figura 5) em Diamante, pode se justificar porque justamente na época de colheita se verificou o período chuvoso (Figura 1) podendo além do mais, esse fenômeno meteorológico ter proporcionado uma maior umidade relativa; essas condições, como se sabe, são favoráveis a ocorrência de fungos, acelerando a deterioração das sementes, bem como possibilitando condições propícias para manifestação e sobrevivência de microorganismos (Tanaka \& Paolinelli, 1984).

\section{CONCLUSÕES}

O grau de umidade por ocasião da colheita foi mais elevado nas sementes colhidas às 7:00 horas, em todos os campos de produção.

Com base na qualidade fisiológica das sementes do algodoeiro, horários entre 9:00 e 15:00 horas, foram os mais indicados para se proceder a colheita.

Independente dos horários de colheita, sementes produzidas em Tacima obtiveram melhor qualidade fisiológica que os demais locais.

Os fungos de maior incidência nas sementes do algodoeiro foram Aspergillus flavus, Fusarium sp. e Rhizopus sp., mais acentuadamente naquelas cultivadas sob sistema irrigado.

\section{REFERÊNCIAS}

ARAÚJO FILHO, F.B. et al. Efeitos de substrato e da desinfestação de sementes de algodão (Gossypium hirsutum L.), sobre a germinação e qualidade das plântulas. In: REUNIÃO NORDESTINA DE BOTÂNICA, 17, 1993, Teresina. Resumos... Teresina: UFPI, 1993. p.166.

BANZATO, D.A.; KRONKA, S.N. Experimentação Agrícola. Jaboticabal: UNESP, 1992. 245p.

BEWLEY, J.D.; BLACK, M. Seeds physiology of development and germination. New York: Plenum Press, 1994. 445p.

BOLONHEZI, D.; ATHAYDE, M.L.F.; LAGO, A.A.; FUZZATO, M.G.; BORTOLETTO, N.; BOLONHEZI, A.C.; CASTRO, J.L.; SORDI, E. Influência da época da semeadura na qualidade fisiológica de sementes de três cultivares de algodoeiro. In: CONGRESSO BRASILEIRO DE ALGODÃO, 2., 1999, Ribeirão Preto. Anais... Campina Grande: EMBRAPA-CNPA, 1999. p.676-679.

BRASIL, Ministério da Agricultura e Reforma Agrária. Regras para Análise de Sementes. Brasília: SNDA/DNDV/CLAV, 1992. 365p.

BRIGANTE, G.P. Efeitos de épocas de colheita e localização dos frutos na planta sobre a qualidade fisiológica das sementes do algodoeiro. Revista Brasileira de Sementes, Brasília, v.14, n.2, p.135-140, 1992.

CARDOSO SOBRINHO, J.; SILVA, J.N.; CORRÊA, P.C.; DIAS, D.C.F.S. Variação das características físicas e fisiológicas das sementes de sorgo (Sorghum bicolor L.) durante a secagem em função de sua localização no secador. Revista Brasileira de Armazenamento, Viçosa, v.24, n.1, p.27-37, 1999. 
CARVALHO, N.M. Maturação de sementes de algodão (Gossypium hirsutum L.). Semente, Brasília, n.0, p.4-7, 1974.

CARVALHO, N.M.; NAKAGAWA, L. Sementes - Ciência, tecnologia e produção. 4 ed. Jaboticabal: FUNEP, 2000. 588p.

COMISSÃO ESTADUAL DE SEMENTES E MUDAS. Delegacia Federal de Agricultura da Paraíba. Normas técnicas para produção de sementes e mudas fiscalizadas. 3 ed. João Pessoa: DFA/PB, 1989. 85p.

DUTRA, A.S.; CASTRO, J.R. Qualidade da semente de algodão herbáceo, em função do grau de umidade e condição de armazenamento na sua conservação. In: CONGRESSO BRASILEIRO DE ALGODÃO, 1., 1997, Fortaleza. Anais... Campina Grande: EMBRAPA - CNPA, 1997. p.591-592.

EGLI, D.B.; TEKRONY, D.M. Soybean seed germination, vigour and field emergence. Seed Science and Technology, Zürich, v.23, p.595-607, 1995.

FIGUEIREDO, A.F. Qualidade das sementes de algodão (Gossypium hirsutum L.) cultivadas em Minas Gerais. Lavras. 1981. 59f. Dissertação (Mestrado em Fitotecnia) - Escola Superior de Agricultura de Lavras. Universidade Federal de Lavras, 1981.

GOULART, A.C.P. Principais fungos transmitidos pelas sementes de soja, feijão, milho e algodão. Correio Agrícola, São Paulo, n.2, p.18-21, 1995.

JULIATTI, F.C.; BIANCO JÚNIOR, R.; SANTOS, C.M.; SANTOS, V.L.M. Sanidade, germinação, vigor e emergência de sementes de cinco cultivares de algodoeiro (Gossypium hirsutum L.) produzidas nas regiões do triângulo mineiro e sul de Goiás. Fitopatologia Brasileira, Brasília, v.22, p.271, 1997 (Suplemento).

KIMATI, H. Doenças do algodoeiro Gossypium spp. In: GALLI, F. Manual de Fitopatologia, São Paulo: Editora Agronômica Ceres, 1980, v.2, p.29-48.

LIMA, E.F.; VIEIRA, R.M.; CARVALHO, J.M.F.C. Influência de Rhizopus sp, A. niger e A. flavus na deterioração de sementes de algodoeiro armazenadas. Fitopatologia Brasileira, Brasília, v.10, n.1, p.99-115, 1995.

MAGUIRE, J.D. Speed of germination-aid in selection and evaluation for seedling emergence and vigour. Crop Science, Madison, v.2, n.1, p.176-177, 1962.

MEDEIROS FILHO, S.; FRAGA, A.C.; SILVEIRA, J.F.; VIEIRA, M.G.G.C.; OLIVEIRA, J.A. Efeitos do tipo e da época de colheita, sobre a qualidade da semente do algodoeiro
(Gossypium hirsutum L.). Ciência e Prática, Lavras, v.17, n.1, p.20-26, 1993.

NEERGAARD, P. Seed pathology. 2 ed. London: Mac Millan Press, 1979. v.2, 1191p.

PASSOS, S.M.G. Algodão. Campinas: Instituto Campineiro de Ensino Agrícola, 1977. 316p.

PESKE, S.T.; HAMER, E. Colheita de sementes de soja com alto grau de umidade. II - Qualidade fisiológica. Revista Brasileira de Sementes, Brasília, v.19, n.1, p.66-70, 1997.

PIZZINATO, M.A.; RAZERA, L.F.; CIA, E.; AMBROSANO, G.M.B. Qualidade de sementes de algodão (Gossypium hirsutum L.) do ensaio regional de variedades paulistas. Summa Phytopathologica, Jaguariúna, v.25, n.2, p. 139-144, 1999.

QUEIROGA, V.P.; BARROS, M.A.L.; VALE, L.V.; MATOS, V.P. Influência da colheita, armazenamento temporário e beneficiamento nos caracteres tecnológicos do algodão herbáceo. Revista Ceres, Viçosa, v.41, n.236, p.337-357, 1994.

REUZEAU, C.; CAVAliÉ, G. Changes in RNA and Protein Metabolism Associated with Alteration in the Germination Efficiency of Sunflower Seeds. Annuals of Botany, Oxford, v.80, p.131-137, 1997.

SAEG. Sistema para análises estatísticas; versão 7.0. Viçosa: Fundação Arthur Bernardes, 1997.

SANTOS, J.P.; MANTOVANI, E.C. Perdas de grão na cultura do milho, pré-colheita, colheita, transporte e armazenamento. Sete Lagoas: EMBRAPA - CNPMS, 1997. 40p.

SILVA, I.P.G.L. Influência da colheita na qualidade fisiológica de sementes do algodoeiro herbáceo. Areia. 1999. 40f. Monografia (Graduação em Agronomia) - Centro de Ciências Agrárias, Universidade Federal da Paraíba, 1999.

SINGH, K.; FRISVAD, J.C.; THRANE, V.; MTHUR, S.B. In the illustred manual on identification of some seed-borne Aspergilli, Fusaria, Penicillia and their mycotoxins. Hellerup: Danish Government Institute of Seed Pathology for Developing Countries (DIGISP), 1991. 133p.

TANAKA, M.A.S.; PAOLINELLI, G.P. Avaliação sanitária e fisiológica de sementes de algodão produzidas em Minas Gerais. Revista Brasileira de Sementes, Brasília. v.6, n.1, p.71-81, 1984.

VIEIRA, R.D.; CARVALHO, N.M. Testes de vigor em sementes. Jaboticabal: FUNEPE, 1994. 164p. 